
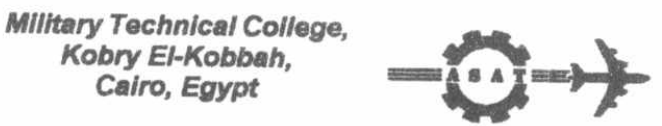

$9^{\text {th }}$ International Conference

On Aerospace Sclences \&

Aviation Technology

\title{
EFFECT OF HEATING AND GAMMA RADIATION ON THE PROPERTIES OF CONCRETE SUITABLE FOR ANTINUCLEAR AIRPLANE SHELTERS
}

\author{
N.A.El-Sharara*, A.M.I.Kany **, M.M.EI-Dessouky* and M.A.Mousa *
}

\begin{abstract}
New heavy weight concrete is proposed to be used in shelters to protect airplanes against shock wave and radiation emitted during nuclear bursts specially gamma and neutrons. In this study, ilmenite is used as a coarse aggregate and serpentine is used as fine aggregate. Different concrete mixes were designed, produced, cured and tested to study the effect of gamma radiation up to $1000 \mathrm{M}$ Rad and temperature up to $500^{\circ} \mathrm{C}$. The results showed that the effect of heating and irradiation on the compressive strength of concrete depends on the elemental composition and on the moisture content of the concrete components.
\end{abstract}

Key Word: Airplane Shelters, Concrete Irradiation, Thermal analysis, Concrete shields.

* Egyptian Armed Forces.

** Al-Azhar University, Faculty of Science, Cairo, Egypt 


\section{Introduction}

The properties of heavy-weight concrete when exposed to high level of gamma radiation and high temperature were studied regarding the mechanical strength, unit weight and thermal properties. The thermal properties of a concrete can be considered to be constant, provided that there is no change in moisture content. However, at elevated temperatures these properties chancye because of changes in the moisture content of the concrete components and because of progressive deterioration of the paste and in some cases of the aggiregates [1]. Normally the compressive strength of concrete when exposed to high temperatures significantly decreases. The magnitude of such decrease dependis on the nature of the aggregates and the initial moisture content of the concrete. It is difficult to separate the effect of irradiation from the effect of temperature. Tests have shown that high level of gamma radiation, reduces the strength of concreti. The energy of absorbed radiation is converted to heat and results in quite large temperature rises in concrete $\left(100^{\circ} \mathrm{C}\right)$ or more in addition to other effects [2].

\section{Experimental Work}

The samples under investigation were prepared in the form of cubes of 1 "side length made from ilmenite-serpentine concrete and ordinary coricrete as a reference. The samples and their compositions are shown in table (1). Tvventy four hours continuos heating at temperatures 100,300 and $500^{\circ} \mathrm{C}$ of ilmenite-serpentine heavy-weight concrete (ISHWC) was carried out. Samples were performed in a box furnace in order to study the effect of heating on unit weight and compressive strength. The irradiation of ISHWC samples were performed in gamrna chamber using CO-60 gamma irradiator [3]. The samples were irradiated at 2, 10,100, 500 and $1000 \mathrm{M}$ Rad, to study the effect of irradiation on the compressive strength of the concrete. The study also includes the differential thermal analysis (D.T.A) of the preheated samples in addition to the thermogravimetric analysis (T.G.A) of the serpentine ore [4].

\section{Results and Discussion}

Effect of heating on the unit weight

The percentage of weight loss of the unheated and heated samples of ISHWC are given in table (2) and Fig.(1). It has been found that the unit weight decreases by heating for all kinds of tested concrete. The extent of decrease in unit weight is affected by the maximum degree of heating. Results show that the maximum amount of decrease was found to be in the riange of heating up to $100^{\circ} \mathrm{C}$. Apparently the maximum weight loss appears at $500^{\circ} \mathrm{C}$. This loss could be due to dissociation of $\mathrm{OH}$ groups exist in the crystal structure of the concrete, which in turn plays an important role in neutron attenuation through , the elastic scattering reaction between fast neutrons and hydrogen atoms. 
Effect of heating on the compressive strength

The effect of heating on the compressive strength is shown in table (2) and Fig.(2). The results indicate that the compressive strength of ISHWC increased by heating up to $100^{\circ} \mathrm{C}$ except sample $\mathrm{B}$, then it began to decrease. For samples $A$ and $B$ the strength is reduced to about $80 \%$ and $62 \%$ respectively of their initial values by heating up to $500^{\circ} \mathrm{C}$. The magnitude of the strength decrease depends on the nature of the aggregates and the initial moisture content of the concrete. The changes in strength has been attributed to a combination of decomposition of the hydrated pastes, deterioration of the aggregates, and thermal incompatibilities between paste and aggregate to stress concentration and microcracking. It is obvious that the role of superplasticizer as water reducing substance improved the compressive strength at temperatures up to $100^{\circ} \mathrm{C}$ only.

\section{Effect of irradiation on the compressive strength}

Results show that there are no significant change in the compressive strength after exposure to gamma doses up to $10 \mathrm{M}$ Rad, while at higher doses and up to $500 \mathrm{M}$ Rad, an apparent decrease in strength (10-25\%) appears, followed by slight decrease at $1000 \mathrm{M}$ Rad as shown in table (4) and Fig.(3). It is noted that when the superplasticizer was added to the concrete, strength was affected (molecule were broken) when exposed to gamma radiation even at low dose of gamma exposure. The plasticized ilmentite-serpentine concrete produced always have the hieghest value of compressive strength among other concrete shields even at high dose of gamma exposure.

Differential Thermal Analysis (D.T.A) and Thermogravimeteric Analysis (T.G.A.) The D.T.A. and T.G.A. curves for the unheated serpentine ore are given in Fig.(4) and Fig.(5). The D.T.A. curve shows a marked endothermic peak at $651^{\circ} \mathrm{C}$. This peak is confirmed by the loss in weight observed in the T.G.A. curve around this temperature. This peak can be attributed to the dehydration of water of crystallization exists in the serpentine ore. The total loss of water in the ore is estimated from the T.G.A. curve and it was found to be $11.59 \%$ of the total sample weight. Fig.(4) also shows that the D.T.A. curves of the preheated serpentine ore of 100,300 and $500^{\circ} \mathrm{C}$. It can be seen from the curves that the endothermic peak are vanished completely for the sample preheated at $750^{\circ} \mathrm{C}$.

\section{Conclusion}

- The ilmentite and serpentine ores can be used to design heavy weight concrete mixes of density up to $3.47 \mathrm{~kg} / \mathrm{m}^{3}$ and of $11.59 \mathrm{wt} \%$ of water content, and hence they can be used safely and effectively to a large extent as coarse and fine aggregates to attenuate both gamma rays and neutrons.

- The ISHWC is a best resistance one regarding both the unit weight and the compressive strength even at high temperatures of heating exposure.

- The ISHWC dose not affect significantly to the exposure of high dose of gamma rays to $1000 \mathrm{M}$ Rad.

- The serpentine ore still retains a significant amount of water up $10600^{\circ} \mathrm{C}$. 


\section{Reference}

[1] Mindess S., Concrete, Prentice-Hall, N.J. (1981).

[2] Neville A.M., Properties of Concrete, Pitman publishing inc., London, (1981).

[3] Purav V.N., Board of Radiation and Isotope Technology, Mumbai, India (1999).

[4] Richard A.F., Engineering material and Their Applications, John Wily \& Sons, N.Y., (1995). 
Table 1 Samples under investigation

\begin{tabular}{|c|c|c|c|c|}
\hline Type of & \multicolumn{3}{|c|}{ Compostions } \\
\cline { 2 - 5 } samples & \% Fine aggregate & Cement content $\mathrm{Kg} / \mathrm{m}^{3}$ & Additives & W/C \\
\hline A & 33 & 400 & - & 0.65 \\
B & 33 & 400 & Superplasticizer & 0.56 \\
C (ordinary & 33 & 350 & - & 0.50 \\
concrete) & & & & \\
\hline
\end{tabular}

Table 2 Effect of heating on unit weight

\begin{tabular}{|c|c|c|c|}
\hline Temperature ${ }^{\circ} \mathrm{C}$ & $\begin{array}{c}\mathrm{A} \\
\text { \% weight loss }\end{array}$ & $\begin{array}{c}\mathrm{B} \\
\text { \% weight loss }\end{array}$ & $\begin{array}{c}\mathrm{C} \\
\text { \% weight loss }\end{array}$ \\
\hline 25 & 0 & 0 & 0 \\
\hline 100 & 2.856 & 2.370 & 2.162 \\
\hline 300 & 4.841 & 4.402 & 4.710 \\
\hline 500 & 6.488 & 6.066 & 4.800 \\
\hline
\end{tabular}

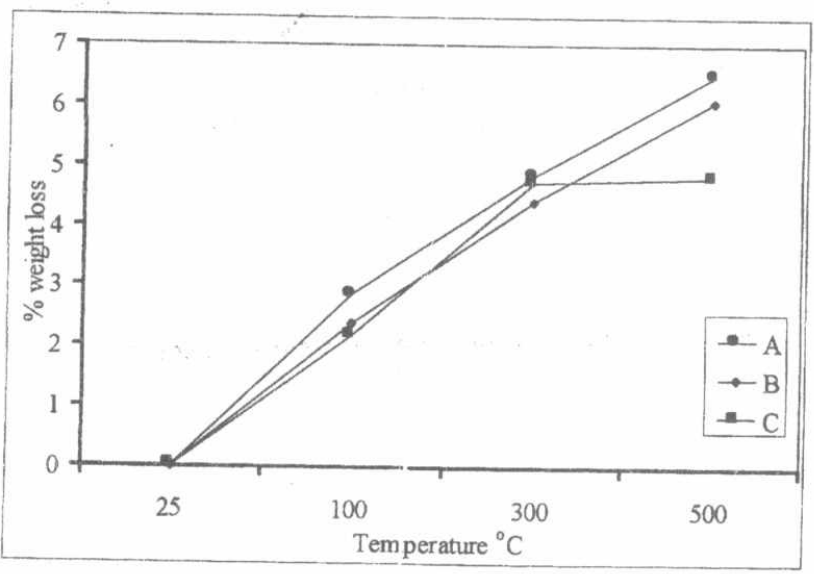

Fig. 1 Effect of heating on the \% of weight loss

Table 3 Effect of heating on compressive strength

\begin{tabular}{|c|c|c|c|}
\hline Temperature ${ }^{\circ} \mathrm{C}$ & $\mathrm{A}$ & $\mathrm{B}$ & $\mathrm{C}$ \\
\hline 25 & 342 & 450 & 270 \\
\hline 100 & 360 & 400 & 300 \\
\hline 300 & 300 & 310 & 150 \\
\hline 500 & 275 & 280 & 100 \\
\hline
\end{tabular}




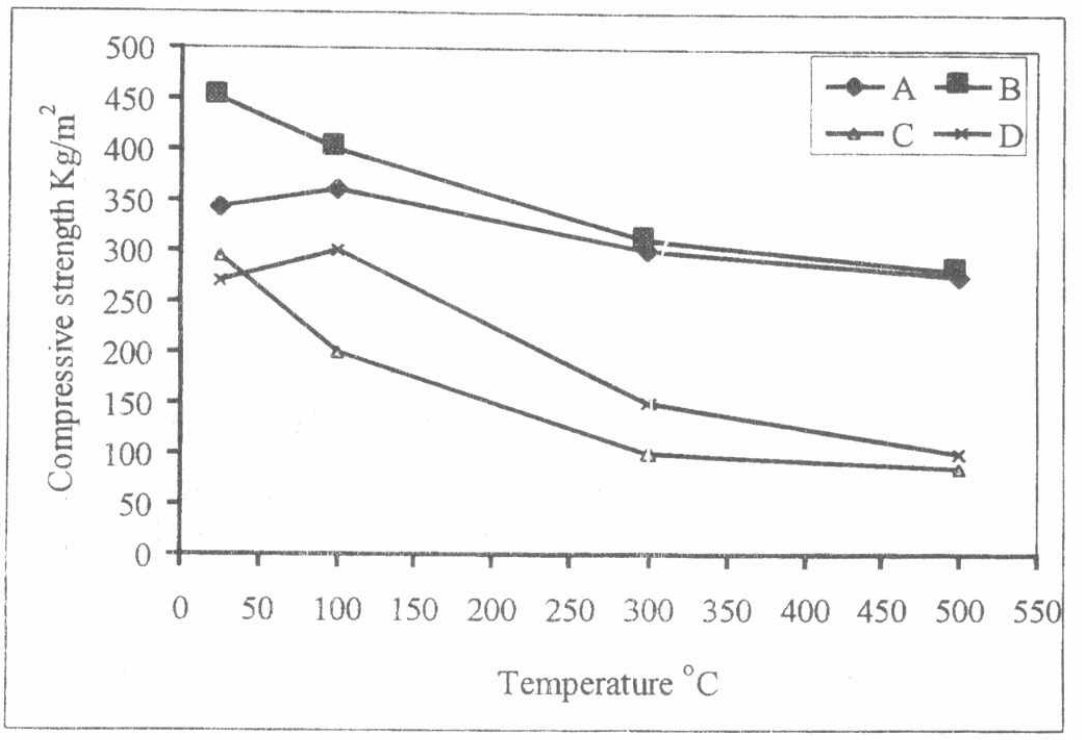

Fig.2 Effect of heating on compressive strength

Table 4 Effect of $\gamma$-irradiation on compressive strength

\begin{tabular}{|c|c|c|c|}
\hline $\begin{array}{c}\text { Gamma dose } \\
\text { MRad }\end{array}$ & A & B & C \\
\hline 0 & 342 & 450 & 270 \\
\hline 2 & 340 & 420 & 250 \\
\hline 10 & 330 & 400 & 250 \\
\hline 100 & 300 & 345 & 200 \\
\hline 500 & 290 & 285 & 180 \\
\hline 1000 & 286 & 275 & 155 \\
\hline
\end{tabular}




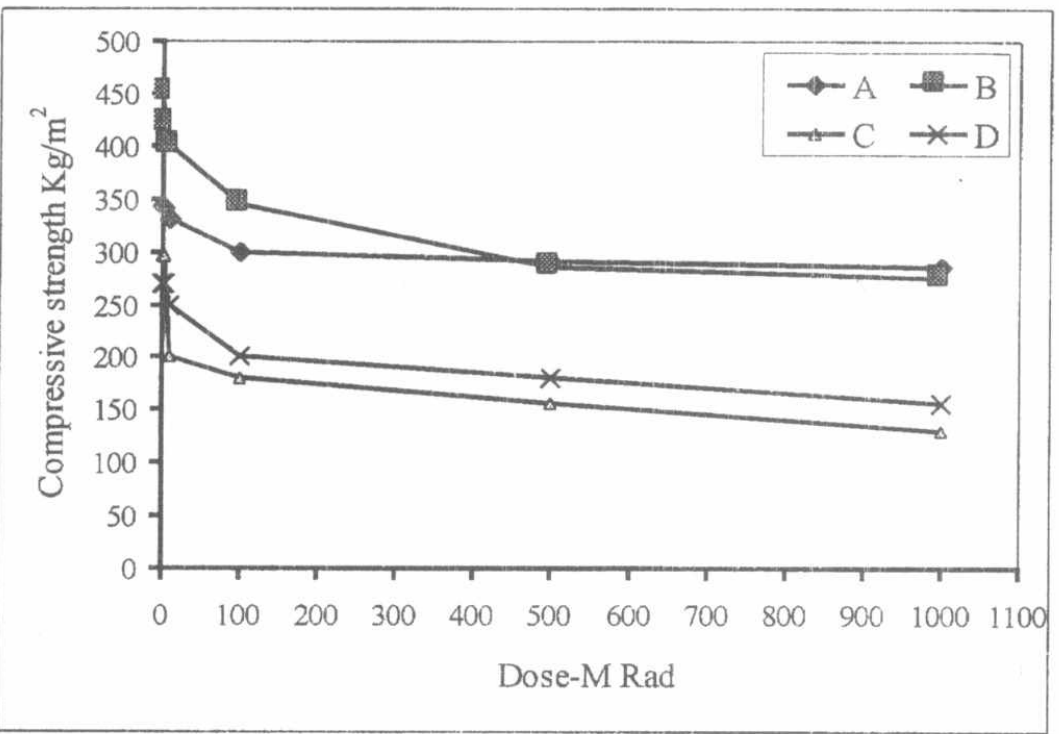

Fig.3 Effect of $\gamma$-irradiation on compressive strength

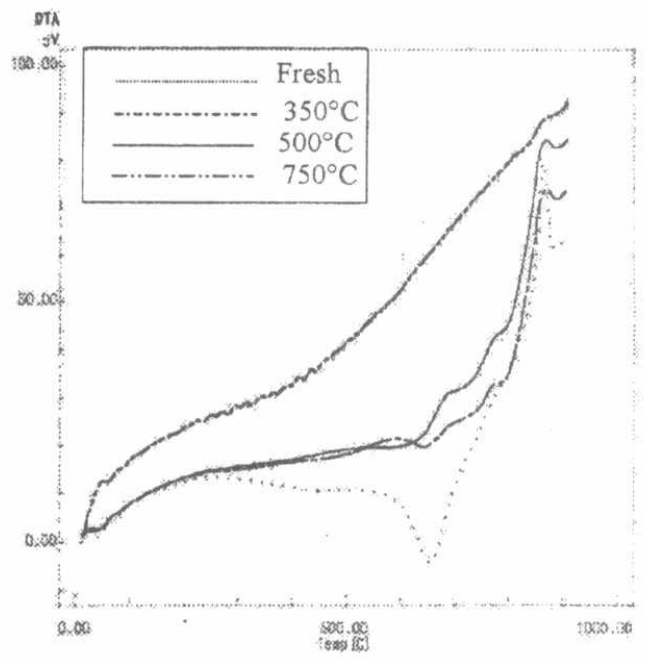

Fig.4 DTA for unheated and heat preheated serpentine rocks 


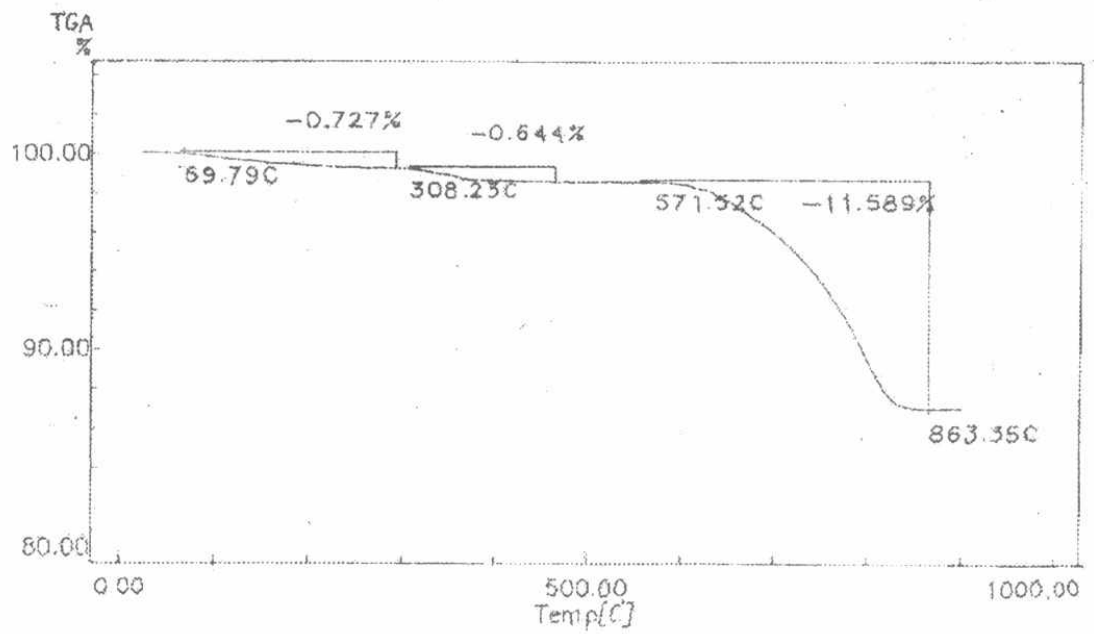

Fig. 5 Thermogravimetric analysis (T.G.A) of serpentine ore 